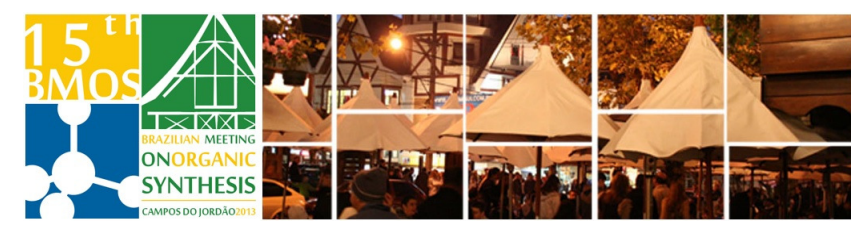

\title{
Studies on the synthesis of (poly)arylacetylenes using cardanol and glycerol as raw materials
}

\author{
Campo Grande - MS, Brasil \\ *adilson.beatriz@ufms.br.
}

Tatiana Matayoshi, Ana Camila Micheletti and Adilson Beatriz ${ }^{*}$

Instituto de Química - INQUI, Universidade Federal de Mato Grosso do Sul - UFMS, CP 549, 79070-900

Keywords: Arylacetylenes, helical polymers, glycerol

\section{INTRODUCTION}

Arylacetylenes are precursors for the construction of conjugated polyarylacetylenes, which have been widely used in the preparation of helical artificial polymers for applications in a variety of fields. The design, synthesis and application of helical polymers with helix direction control, have become a field of great interest in recent years. ${ }^{1}$ Physical, chemical and electric stimuli interfere dramatically in structure, form and morphology of these polymers, resulting in great importance to achieve smart materials. In achiral (poli)arylacetylenes, the macromolecular helicity with a preferential direction of the helix can be induced by the presence of a chiral component, incorporated into the main chain or into the mesogenic units, making the polymer to serve as a chiral sensor. Rod-shaped helical polymers with an excess of one of the propellers, frequently show chiral liquid-crystalline phase. ${ }^{2}$ Given the importance of these polymers, herein we present a study of synthetic conditions for preparing arylacetylenes from national industry byproducts, cardanol (1) (as pendant and mesogenic unit) and glycerol (chiralityinducer) aiming to obtain innovative helical chiral polymers with liquid crystalline features.

\section{RESULTS AND DISCUSSION}

The chlorohydrin (3) and epoxide (4) were obtained from the reaction of cardanol (1) and epichlorohydrin (2) (derived from glycerol) and used as electrophiles in a $S_{N} 2$ reaction with ethynylaniline (5) to give the arylacetylene (6) (Fig. 1).

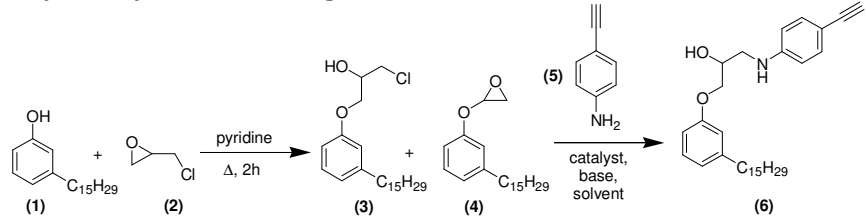

Figure 1. Schematic representation for the synthesis of (6) from (1) and (2).

The $S_{N} 2$ reaction above has proved be tough and some reaction conditions were performed for the coupling between the mixture of (3) and (4) with (5), as shown in Table 1. Structures of the products were elucidated by NMR analyses.
Table 1. Reactional conditions for the synthesis of (6)

\begin{tabular}{ccccccc}
\hline & Solvent & Catalyst & Base & $\begin{array}{c}\text { Time } \\
(\mathbf{h})\end{array}$ & $\mathbf{T}\left({ }^{\circ} \mathbf{C}\right)$ & $\begin{array}{c}\text { Product } \\
\text { /yeld }\end{array}$ \\
\hline 1 & $\mathrm{CH}_{2} \mathrm{Cl}_{2}$ & Nal & pyridine & 4 & $*$ & - \\
2 & $\mathrm{THF}^{3}$ & alumin & - & 6 & reflux & - \\
3 & $\mathrm{ACN}^{4}$ & $\mathrm{CoCl}_{2}{ }^{* *}$ & - & 3 & reflux & $\mathbf{7 / 5 0 \%}$ \\
4 & $\mathrm{DMSO}^{*}$ & - & pyridine & 3 & reflux & - \\
5 & $\mathrm{CH}_{2} \mathrm{Cl}_{2}{ }^{5}$ & $\begin{array}{c}\text { Amberlist } \\
15\end{array}$ & - & 3 & reflux & - \\
6 & $\mathrm{ACN}^{2}$ & - & pyridine & 24 & reflux & $\mathbf{6 / 4 0 \%}$ \\
\hline
\end{tabular}

${ }^{*}$ Sealed tube. ${ }^{\star *} \mathrm{~N}_{2}$ atmosphere.

The entry 3, using $\mathrm{CoCl}_{2}$ as catalyst, was most effective to couple the reagents, however, led to hydrolysis of the alkyne to methyl ketone 7 , in $50 \%$ yield.

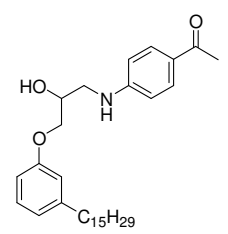

(7)

\section{CONCLUSION}

The desired arylacetylene (6) could be successfully synthesized using a classical $\mathrm{S}_{\mathrm{N}} 2$ approach, and will be used in our continuous research to produce helical chiral polymers with liquid crystalline features.

\section{ACKNOWLEDGEMENTS}

FUNDECT-MS, PROPP-UFMS, CNPq and CAPES.

\section{REFERENCES}

${ }^{1}$ Louzao, I.; Seco, J. M.; Quiñoa, E. e Riguera, R. Angew. Chem. Int. Ed. 2010, 49, 1. ${ }^{2}$ Maeda, K.; Kamiya, N. e Yashima, E. Chem. Eur. J. 2004, 10, 4000. ${ }^{3}$ Harrak, Y. e Pujol M. D. Tetrahedron Lett. 2002, 43, 819. ${ }^{4}$ Iqbal, J. e Pandey, A. Tetrahedron Lett. 1990, 31, 575. ${ }^{5}$ Vijender, M.; Kishore, P.; Narender, P. e Satyanarayana, B. J. Mol. Catal. A: Chem. 2007, 266, 290.

$15^{\text {th }}$ Brazilian Meeting on Organic Synthesis - 15 $5^{\text {th }}$ BMOS - November 10-13, 2013 - Campos do Jordão, Brazil 